\title{
Caracterização de Escherichia coli diarreiogênica isolada de água subterrânea para consumo humano em um assentamento rural
}

\section{Characterization of diarrheagenic Escherichia coli isolated from underground water for human consumption in a rural settlement}

\author{
Kawana Hiromori Macedo ${ }^{1}$, Caroline Rodrigues da Silva², Angélica Marim \\ Lopes Dambrozio ${ }^{3}$, Anahí Lara Klein ${ }^{4}$, Wellington Danilo de Oliveira ${ }^{4}$, \\ Matheus Silva Sanches ${ }^{5}$, Sérgio Paulo Dejato da Rocha ${ }^{6}$, \\ Armando Navarro Ocaña ${ }^{7}$, Jacinta Sanchez Pelayo ${ }^{8}$
}

\section{Resumo}

Escherichia coli diarreiogênica (DEC) é um importante agente de infecções gastrointestinais transmitidas pela água. $\mathrm{O}$ trabalho teve como objetivo avaliar a qualidade microbiológica e físicoquímica de 58 amostras de água subterrânea in natura para consumo de um assentamento rural e caracterizar os isolados de E. coli, genotipicamente dentro dos patotipos de DEC, pela técnica da PCR, e fenotipicamente. Todas as amostras apresentaram contaminação por coliformes totais e 36 $(62,1 \%)$ por E. coli. Em células HEp-2, dos 170 isolados de E. coli, $106(62,36 \%)$ apresentaram AA, $15(8,82 \%) \mathrm{AD}, 17(10 \%)$ adesão não caracterizado e $32(18,82 \%)$ foram não aderentes. Quanto à formação de biofilme, $126(74,12 \%)$ cepas são formadoras, e $44(25,88 \%)$ não formaram biofilme. Foram identificadas DEC em 6,89\% das amostras de água: três (5,17\%) ETEC e uma (1,72\%) EAEC. EAEC apresentou AA e as três cepas de ETEC apresentaram AD, AA e não definida. Todas as DEC foram formadoras de biofilme. Dois isolados de ETEC apresentaram resistência à ampicilina e tetraciclina, uma ETEC à aminoglicosídeos, e EAEC foi sensível a todos os antibióticos testados. As ETEC foram classificadas no filogrupo B1 e a EAEC no E. Os sorotipos encontrados foram: O24:H21, OR:H21, O17:H46 e O6:H12. Todas as amostras estavam dentro dos parâmetros normais de flúor e $13(22,4 \%)$ apresentaram resultados acima do padrão permitido de turbidez. A presença de E. coli e DEC nas amostras de água indica a necessidade de adoção de medidas que evitem a contaminação da água fornecida à população, evitando, assim, a transmissão de doenças.

Palavras-chave: DEC. Água in natura. Assentamento.

\footnotetext{
${ }^{1}$ Mestrado em Microbiologia pelo Programa de Pós-graduação em Microbiologia da Universidade Estadual de Londrina, Londrina, Paraná, Brasil. E-mail: kawana_hiromore@hotmail.com

${ }^{2}$ Doutoranda em Ciências da Saúde na Faculdade de Medicina de São José do Rio Preto, São José do Rio Preto, São Paulo, Brasil.

${ }^{3}$ Doutorado em Microbiologia pelo Programa de Pós-graduação em Microbiologia da Universidade Estadual de Londrina, Londrina, Paraná, Brasil.

${ }^{4}$ Mestrado em Microbiologia pelo Programa de Pós-graduação em Microbiologia da Universidade Estadual de Londrina, Londrina, Paraná, Brasil.

${ }^{5}$ Doutorando em Microbiologia no Programa de Pós-graduação em Microbiologia da Universidade Estadual de Londrina, Londrina, Paraná, Brasil.

${ }^{6}$ Doutorado em Ciências (Biotecnologia) pela Universidade de São Paulo, São Paulo, São Paulo, Brasil. Professor Adjunto do Depto. de Microbiologia do Centro de Ciências Biológicas da Universidade Estadual de Londrina, Londrina, Paraná, Brasil.

${ }^{7}$ Departamento de Salud Pública, Facultad de Medicina, Universidad Nacional Autónoma de México, México.

${ }^{8}$ Doutorado em Ciências Biológicas (Microbiologia) pela Universidade de São Paulo, São Paulo, São Paulo, Brasil. Professora Associada do Departamento de Microbiologia do Centro de Ciências Biológicas da Universidade Estadual de Londrina, Londrina, Paraná, Brasil.
} 


\begin{abstract}
Diarrheogenic Escherichia coli (DEC) is an important agent of waterborne gastrointestinal infections. The objective of this work was to evaluate the microbiological and physico-chemical quality of 58 freshwater groundwater samples for the consumption of a rural settlement and to characterize the E. coli isolates, genotyped within the DEC pathophyses, by the PCR technique, and phenotypically. All water samples presented contamination with total coliforms, and $36(62.1 \%)$ with $E$. coli. In HEp-2 cells, of 170 E. coli isolates, 106 (62.36\%) showed AA, 15 (8.82\%) AD, 17 (10\%) noncharacterized adhesion and $32(18.82 \%)$ were non-adherent. As for biofilm formation, $126(74.12 \%)$ strains are forming, and $44(25.88 \%)$ did not form biofilm. DEC was identified in $6.89 \%$ of the water samples with E. coli: three (5.17\%) with enterotoxigenic E. coli (ETEC), and one (1.72\%) with enteroaggregative E. coli (EAEC). EAEC showed aggregative adherence, whereas various ETEC strains presented diffuse, aggregative, and non-defined adherence. All DEC strains were biofilm forming. Two isolates of ETEC showed resistance to ampicillin and tetracycline, and one isolate showed resistance to aminoglycosides. The EAEC isolate was sensitive to all antibiotics tested. All ETECs were classified into phylogenetic B1 and EAEC in E. The serotypes identified in our study were: O24:H21, ONT:H21, O17:H46, and O6:H12. All water samples were within normal fluorine parameters; however, measured turbidity was above the permitted standard in $13(22.4 \%)$ samples. The presence of $E$. coli and DEC in water samples indicates the need to take action to prevent contamination of water resources accessed by people to prevent the transmission of diseases.
\end{abstract}

Keywords: DEC. Water in natura. Settlement.

\section{Introdução}

As doenças de veiculação hídrica, consideradas um importante problema de saúde pública, são originadas principalmente do contato com água contaminada com patógenos entéricos. Em países em desenvolvimento, tanto adultos como crianças sofrem de doenças diarreicas infecciosas, sendo a água a principal fonte de exposição. ${ }^{(1)}$ Segundo a Organização Mundial da Saúde (OMS), ${ }^{(2)}$ todos os anos 361 mil crianças com menos de cinco anos, no mundo, morrem devido à diarreia provocada pela falta de saneamento básico e pela água contaminada.

Em locais como os assentamentos rurais, onde não há infraestrutura adequada e a condição higiênico-sanitária é baixa, é comum não ter abastecimento de água público.Assim, os assentados procuram soluções alternativas, abastecendo-se por meio de água proveniente de fontes subterrâneas, como poços rasos ou minas, que, em sua maioria, estão sujeitas à contaminação. ${ }^{(3)}$

As bactérias do grupo coliforme são frequentemente utilizadas para a avaliação da qualidade microbiológica da água, sendo que, desse grupo, a presença de Escherichia coli, uma bactéria termotolerante de origem exclusivamente fecal, possui uma grande importância clínica. ${ }^{(1)}$

E. coli diarreiogênica (DEC) é uma das causas relacionadas a infecções gastrointestinais no homem, e estão divididas em oito grupos: E. coli enteropatogênica (EPEC), E. coli enterotoxigênica (ETEC), E. coli enteroinvasora (EIEC), E. coli produtora de toxina Shiga (STEC) e seu subgrupo, E. coli enterohemorragica (EHEC), E. coli enteroagregativa (EAEC), E. coli de adesão difusa (DAEC) e E. coli aderente invasora (AIEC), ${ }^{(4)}$ sendo os cinco primeiros os principais patotipos pesquisados.

A diferenciação e a classificação de DEC podem ser realizadas baseadas na presença de diferentes genes de virulência cromossômico e/ou plasmidial que estão ausentes na $E$. coli comensal. A utilização de técnicas moleculares permitiu uma identificação mais rápida dos diferentes patotipos, já que os métodos fenotípicos convencionais, como a detecção de toxinas, aderência e testes de invasão necessitam de mais tempo. ${ }^{(5)}$

EPEC é caracterizada por provocar uma lesão intestinal conhecida como A/E (attaching- 
effacing) e por possuir os genes eae (intimina) e $b f p A$ (codifica uma adesina fimbrial do tipo IV). São subdividas em dois grupos: EPEC típica (tEPEC) e EPEC atípica (aEPEC), considerando a presença ou ausência do gene $b f p A$, respectivamente. ${ }^{(5)}$

As EAEC são identificadas principalmente pelo padrão de adesão agregativo (AA) em cultura de células, entretanto, devido às dificuldades de realizar esse teste, diagnósticos moleculares têm sido desenvolvidos para a detecção de EAEC como alternativa ao teste de adesão. ${ }^{(5)}$ Assim, os genes aggR (aggregative adherence regulator) e aatA (anti-aggregation protein transporter), presentes no plasmídeo de alto peso molecular (pAA), bem como os genes cromossomais aaiA e aaiC, são os mais utilizados para identificar genotipicamente um maior número de EAEC e para classificar esse grupo em EAEC típica (tEAEC) que apresenta o gene regulador $\operatorname{agg} R$, e EAEC atípica (aEAEC) paras as que não apresentam esse gene. ${ }^{(5)}$

STEC é identificada pela presença do gene stx 1 e/ou stx 2 associados à produção da toxina Shiga 1 e 2. EHEC é um subgrupo de STEC, que além de produzir toxina Shiga possui o gene eae. ${ }^{(5)}$ ETEC tem dois principais fatores associados à virulência, as enterotoxinas termo estável (ST) e termo lábil (LT). EIEC é caracterizada pela presença do gene $i p a H$, presente em um plasmídeo de alto peso molecular, associado ao mecanismo de invasão. ${ }^{(5)}$

Esse estudo teve como objetivo avaliar a qualidade microbiológica e físico-química da água em um assentamento rural localizado na Região Sul do Brasil, e a caracterização genotípica e fenotípica de fatores de virulência de DEC nos isolados de E. coli encontradas nas amostras de água analisadas.

\section{Material e Métodos}

\section{Amostras}

O estudo foi realizado com 58 amostras de água in natura para consumo humano provenientes de 24 minas e 8 poços rasos de um assentamento com aproximadamente 60 moradias e uma população de 150 habitantes, localizado na Região Sul do
Brasil, coletadas no período de julho a dezembro de 2016. As amostras foram coletadas em frascos de vidro de $500 \mathrm{ml}$ esterilizados e armazenadas a $4{ }^{\circ} \mathrm{C}$, sendo analisadas em, no máximo, seis horas no Laboratório de Bacteriologia (Departamento de Microbiologia, CCB, Universidade Estadual de Londrina - UEL, Londrina, Paraná).

\section{Análise físico-química da água}

A caracterização físico-química foi realizada mediante os parâmetros turbidez, pesquisado pelo método Nefelométrico e de fluoreto pela técnica de potenciometria, com um eletrodo íon seletivo de fluoreto de lantânio, segundo a American Public Health Association (APHA) ${ }^{(6)}$

\section{Análise de coliformes totais e E. coli}

A técnica utilizada para detecção e quantificação de coliformes totais e E. coli foi a do substrato cromogênico Colilert ${ }^{\circledR}$ (SOVEREIGN USA), aprovado pela American Public Health Association $^{(6)}$ e realizada como descrita por Schuroff et al. ${ }^{(7)}$

Após a incubação a $37{ }^{\circ} \mathrm{C}$ por vinte e quatro horas das cartelas Quanti-Tray (WP2000), as estimativas quantitativas de Número Mais Provável (NMP) de coliformes totais e E. coli foram determinadas de acordo com as instruções do fabricante.

\section{Isolamento de E. coli}

Para o isolamento de E. coli, foram retiradas alíquotas dos poços amarelos das cartelas do kit cromogênico Colilert ${ }^{\circledR}$ que apresentaram coloração azul-fluorescente frente à luz UV, indicando assim a presença de E. coli, e semeadas em placa de ágar MacConkey (MC) (Difco ${ }^{\circledR}$, USA) sendo incubadas a $37{ }^{\circ} \mathrm{C}$ por vinte e quatro horas. De cada placa de $\mathrm{MC}$ foram selecionadas de três a cinco colônias e identificadas bioquimicamente por meio do kit EPM, MILi e Citrato de Simmons (PROBAC, BR). Um total de 170 isolados de 
E. coli foram obtidos e armazenados em caldo infusão de coração e cérebro (BHI) $\left(\right.$ Difco $\left.^{\circledR}\right)$ com $20 \%$ de glicerol $\left(\right.$ Sigma $\left.^{\circledR}\right)$ a $-20{ }^{\circ}$ C.

\section{Pesquisa de genes de virulência} através da PCR

Todos os isolados de E. coli foram testados quanto à presença dos genes de virulência de EPEC (eae, $b f p A), \operatorname{STEC}\left(s t x_{1}, s t x_{2}\right), \operatorname{EHEC}\left(e a e, s t x_{1}, s t x_{2}\right)$, EAEC (aaiC, aatA, aggR e aaiA), ETEC (LT, ST-Ia e $S T-I b)$ e EIEC (ipaH). Como controle positivo para os genes eae, bfp $A$ foi utilizada a $E$. coli E2348/69 (O127:H6), para os genes $s t x_{1}$, stx 2 a EDL933 (E. coli $\mathrm{O} 157: \mathrm{H7}$ ), para os genes aaiC, aaiA, aatA e $\operatorname{aggR}$ a EAEC 042 (O44:H18), para os genes ST-Ia, ST-Ib e LT a ETEC H10407 (O78:K80:H11) e para o gene ipaH a EIEC FBC124-13 (O124:NM). A cepa HB101 (E. coli $\mathrm{K}-12$ ) foi utilizada como controle negativo para todos os testes.

O DNA bacteriano foi obtido pelo método de extração por fervura segundo Lascowski et al. ${ }^{(8)}$ Os isolados de E. coli foram cultivados em caldo
Luria-Bertani (LB) $\left(\right.$ Difco $\left.^{\circledR}\right)$ a $37{ }^{\circ} \mathrm{C}$ por vinte e quatro horas. Foram transferidos $1,5 \mathrm{~mL}$ da cultura bacteriana para microtubos e em seguida centrifugados a 10.000 x g por dez minutos. $\mathrm{O}$ precipitado foi suspendido em $300 \mu \mathrm{L}$ de água ultrapura estéril, submetida à fervura por dez minutos e centrifugadas a $10.000 \mathrm{x}$ g por cinco minutos. Os sobrenadantes foram utilizados nos ensaios da PCR.

As reações de amplificações foram realizadas no termociclador GeneAmp ${ }^{\circledR}$ PCR System 9700 thermal cycler (Applied Biosystems, USA), com um volume final de $25 \mathrm{iL}$, composto por $200 \mathrm{iM}$ dNTPs (Invitrogen ${ }^{\circledR}$ ), 2,5 iM $\mathrm{MgCl}_{2}, 1 \mathrm{X}$ tampão do PCR, 20 pmol de cada primer (Invitrogen ${ }^{\circledR}$ ), $1 \mathrm{U}$ de Taq DNA polimerase $\left(\right.$ Invitrogen $^{\circledR}$ ), 2 iL do lisado bacteriano. As amplificações foram visualizadas em eletroforese de gel de agarose a $1,5 \%$ com o corante SYBR Safe ${ }^{\mathrm{TM}}$ DNA Gel Stain $\left(\right.$ Invitrogen $^{\circledR}$ ). A Tabela 1 mostra as sequências dos oligonucleotídeos iniciadores e tamanho dos fragmentos de DNA amplificados que foram utilizados.

Tabela 1 - Sequência dos oligonucleotídeos pesquisados e tamanho dos fragmentos de DNA amplificados.

\begin{tabular}{|c|c|c|c|}
\hline Gene & Sequência de oligonucleotídeos $\left(5^{\prime}-3^{\prime}\right)$ & $\begin{array}{l}\text { Tamanho dos } \\
\text { fragmentos (pb) }\end{array}$ & Referência \\
\hline bfp $A$ & $\begin{array}{l}\text { (F) TCTGCAATGGTGCTTGCGCTTG } \\
\text { (R) CAGTTGCCGCTTCAGCAGGAGT }\end{array}$ & 478 & Vendruscolo et al..$^{(9)}$ \\
\hline eae & $\begin{array}{l}\text { (F) GACCCGGCACAAGCATAAGC } \\
\text { (R) CCACCTGCAGCAACAAGAGG }\end{array}$ & 384 & Paton e Paton $^{(10)}$ \\
\hline stx 1 & $\begin{array}{l}\text { (F) ATAAATCGCCATTCGTTGACTAC } \\
\text { (R) AGAACGCCCACTGAGATCATC }\end{array}$ & 180 & Paton e Paton $^{(10)}$ \\
\hline stx 2 & $\begin{array}{l}\text { (F) GGCACTGTCTGAAACTGCTCC } \\
\text { (R) TCGCCAGTTATCTGACATTCTG }\end{array}$ & 255 & Paton e Paton ${ }^{(10)}$ \\
\hline aaiC & $\begin{array}{l}\text { (F) ATTGTCCTCAGGCATTTCACACG } \\
\text { (R) ACACCCCTGATAAACAA }\end{array}$ & 215 & Lima et al..$^{(11)}$ \\
\hline aaiA & $\begin{array}{l}\text { (F) CCCACGACCAGATAACG } \\
\text { (R) GTTTTCAGGATTGCCATTAG }\end{array}$ & 476 & Dudley et al..$^{(12)}$ \\
\hline aatA & $\begin{array}{l}\text { (F) CTGGCGAAAGACTGTATCATC } \\
\text { (R) AATGTATAGAAATCCGCTGTT }\end{array}$ & 630 & Schmidt et al..$^{(13)}$ \\
\hline
\end{tabular}


Continuação

$\begin{array}{cccc}\text { aggR } & \text { (F) CGATACATTAAGACGCCTAAAG } & 346 & \begin{array}{c}\text { Andrade, Gomes } \\ \text { e Elias }\end{array} \\ \text { (R) TCTGATACATTAAATTCATCTGC } & & \begin{array}{c}\text { Aranda, Fagundes } \\ \text { e Scaletsky(15) }\end{array} \\ \text { (F) GTTCCTTGACCGCCTTTCCGATACCGTC } & 600 & \begin{array}{c}\text { Aranda, Fagundes } \\ \text { e Scaletsky }\end{array} \\ & \text { (R) GCCGGTCAGCCACCCTCTGAGAGTAC } & & \text { Schultsz }^{(16)} \\ S T-I a & \text { (F) GGCGACAGATTATACCGTGC } & 450 & \\ & \text { (R) CGGTCTCTATATTCCCTGTT } & 186 & \text { Schultsz }^{(16)} \\ S T-I b & \text { (F) TCTGTATTATCTTTCCCCTC } & & \end{array}$

Fonte: Autores

Teste de adesão em células HEp-2

O teste de adesão foi realizado com todos os isolados de E. coli, utilizando-se células epiteliais HEp-2, segundo a técnica descrita por Cravioto et al., ${ }^{(17)}$ após seis horas de interação bactéria-célula. Este teste permite caracterizar fenotipicamente os diferentes padrões de adesão apresentados pelos patotipos de DEC, classificadas em: adesão localizada (AL), agregativa (AA), localizada - like (AL-L) e difusa (AD). ${ }^{(5)}$

\section{Formação de biofilme}

A formação de biofilme foi realizada de acordo com o método descrito por Wakimoto et al. ${ }^{(18)}$ A formação de biofilme foi considerada positiva ao apresentar um resultado superior a 0,2 quando realizado uma leitura de densidade óptica (DO) a $570 \mathrm{~nm}$.

\section{Sensibilidade a antimicrobianos}

Nas amostras de DEC, a sensibilidade aos antimicrobianos foi determinada pelo método de disco difusão em ágar de acordo com as recomendações do Clinical and Laboratory Standards Institute. ${ }^{(19)}$ Os seguintes antimicrobianos $\left(\right.$ Laborclin $\left.^{\circledR}, \mathrm{BR}\right)$ foram testados: ampicilina $(10 \mu \mathrm{g})$, tetraciclina $(30 \mu \mathrm{g})$, cefoxitina $(30 \mu \mathrm{g})$, cefalotina
$(30 \mu \mathrm{g})$, ciprofloxacina $(5 \mu \mathrm{g})$, ácido nalidíxico $(30 \mu \mathrm{g})$, piperacilina tazobactam $(100 / 10 \mu \mathrm{g})$, ampicilina sulbactam $(10 / 10 \mu \mathrm{g})$, amicacina $(30 \mu \mathrm{g})$, gentamicina $(10 \mu \mathrm{g})$ e cloranfenicol $(30 \mu \mathrm{g})$.

\section{Classificação filogenética}

A classificação filogenética foi realizada por PCR com as cepas de DEC. Os genes chuA, yjaA, $\operatorname{arp} A, \operatorname{trp} A$ e o fragmento de DNA TSPE4.C2, por meio de uma PCR, foram empregados para caracterização dos grupos filogenéticos A, B1, B2, C, D, E, F, de acordo com Clermont et al. ${ }^{(20)}$

\section{Sorotipagem}

A determinação dos antígenos somáticos (O1-O187) e flagelares (H1-H56) de E. coli foi realizada na Universidad Nacional Autónoma de México - UNAM (Ciudad Universitaria, México).

\section{Resultados}

Em nosso estudo, foram analisadas 58 amostras de água in natura para consumo humano, coletadas de fontes subterrâneas, entre elas, poços rasos e minas, e todas apresentaram contaminação por coliformes totais, e $36(62,1 \%)$ por E. coli. Das amostras que apresentaram fluorescência nas cartelas Quanti-Tray (WP2000), foram isoladas 170 cepas de 
E. coli. Segundo os ensaios de aderência em células HEp-2 realizado com os isolados, o padrão AA foi encontrado em 106 (62,36\%) isolados de E. coli, 15 $(8,82 \%)$ apresentaram o padrão $\mathrm{AD}, 17(10 \%)$ não apresentaram um padrão de adesão caracterizado e $32(18,82 \%)$ isolados foram não aderentes.

Todos os isolados foram avaliados quanto à capacidade de formação do biofilme, 126 (74,12\%) cepas exibiram DO $570 \mathrm{~nm}$ acima de 0.2 , sendo consideradas formadoras de biofilme, e 44 (25,88\%) cepas obtiveram DO $570 \mathrm{~nm}$ abaixo e/ou igual 0.2, portanto consideradas não formadoras de biofilme. As quatro amostras de DEC encontradas nesse trabalho foram formadoras de biofilme.
As 170 cepas de E. coli foram testadas para a presença de doze genes de virulência que caracterizam os diferentes patotipos de DEC. Foi identificado DEC em quatro amostras de água $(11,11 \%)$, sendo três $(8,33 \%)$ amostras com ETEC, em que duas apresentaram o gene $S t-I b$ e uma os genes $L t$ e $S t-I a$, e uma $(2,77 \%)$ EAEC com o gene aaiA, sendo caracterizada como aEAEC. Todas as amostras de ETEC foram isoladas de água de mina e a aEAEC de poço raso. Nenhuma amostra apresentou os genes para STEC, EHEC E EIEC. As características genotípicas e fenotípicas das amostras positivas para DEC podem ser observadas na Tabela 2.

Tabela 2 - Características genotípicas e fenotípicas das amostras de DEC.

\begin{tabular}{|c|c|c|c|c|c|c|c|}
\hline Amostra & $\begin{array}{l}\text { Patotipos } \\
\text { de DEC }\end{array}$ & $\begin{array}{c}\text { Genes de } \\
\text { virulência }\end{array}$ & $\begin{array}{c}\text { Adesão em } \\
\text { células HEp-2 }\end{array}$ & $\begin{array}{c}\text { Grupo } \\
\text { filogenético }\end{array}$ & Sorotipo & Biofilme & $\begin{array}{c}\text { Perfil de } \\
\text { resistência }\end{array}$ \\
\hline 6.3 & aEAEC & aaiA & $\begin{array}{c}\text { Adesão } \\
\text { agregativa }\end{array}$ & E & $\mathrm{O} 24: \mathrm{H} 21$ & + & Sensível \\
\hline 8.4 & ETEC & $L t, S t-a$ & $\begin{array}{c}\text { Adesão } \\
\text { difusa }\end{array}$ & B1 & OR:H21 & + & AMP, TET \\
\hline 45.5 & ETEC & $S t-b$ & $\begin{array}{c}\text { Adesão } \\
\text { não definida }\end{array}$ & B1 & O17:H46 & + & AMP, TET \\
\hline 46.1 & ETEC & $S t-b$ & $\begin{array}{c}\text { Adesão } \\
\text { agregativa }\end{array}$ & B1 & O6:H12 & + & AMI, GEN \\
\hline
\end{tabular}

Fonte: Autores

AMP: ampicilina; TET: tetraciclina; AMI: amicacina; GEN: gentamicina.

As amostras positivas para DEC apresentaram diferentes padrões de adesão, as cepas de ETEC apresentaram os padrões $\mathrm{AD}, \mathrm{AA}$ e adesão não definida, e a aEAEC expressou o padrão AA. Em relação aos antimicrobianos, duas cepas de ETEC apresentaram resistência à ampicilina e tetraciclina e uma à amicacina e gentamicina. $\mathrm{O}$ isolado de aEAEC foi sensível a todos os antimicrobianos testados. Segundo a análise filogenética, as três amostras de ETEC se enquadraram no filogrupo B1 e a aEAEC no filogrupo E. Os sorotipos encontrados em nosso estudo foram: EAEC O24:H21 e ETEC OR:H21, O17:H46 e O6:H12.
De acordo com os resultados das análises físico-químicas, um total de $13(22,4 \%)$ amostras de água se encontra acima do limite permitido de turbidez e todas as amostras estão dentro dos parâmetros de flúor.

\section{Discussão}

Conforme as normas da Portaria do

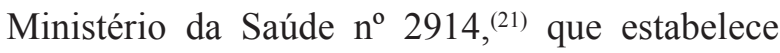
o limite máximo de $1,5 \mathrm{mg} / \mathrm{L}$ para fluoreto e 5,0 UNT (Unidade Nefelométrica de Turbidez) para turbidez, todas as amostras analisadas apresentaram 
limite inferior a $1,5 \mathrm{mg} / \mathrm{L}$ para fluoreto e estavam dentro dos limites permitidos. Os valores elevados de turbidez estão relacionados à redução da transparência da água e podem ser provocados por partículas em suspensão, pela própria natureza das rochas, ou devido à manutenção inadequada das tubulações, sendo um problema para os consumidores que utilizam água de poço. Em um estudo realizado por Scorsafava et al. ${ }^{(22)}$ foram encontrados 10,8\% das amostras coletadas de poços e $5,2 \%$ de minas com alterações nos níveis de turbidez, e duas amostras acima do limite de flúor, resultados que corroboram com os obtidos em nosso estudo.

O Ministério da Saúde, por meio da Portaria $\mathrm{n}^{\mathrm{o}} 2914{ }^{(21)}$ recomenda que seja analisada a presença de coliformes totais e E. coli para avaliar a qualidade microbiológica da água para consumo, e esses microrganismos devem estar ausentes na água consumida. Os resultados das análises microbiológicas obtidos em nosso estudo foram similares ao de outro estudo realizado na mesma região. ${ }^{(23)}$ Em contrapartida, em uma pesquisa realizada com amostras de água coletadas em 107 Centros Municipais de Educação Infantil das cidades de Londrina, Cambé, Ibiporã e Rolândia no estado do Paraná, provenientes do sistema de abastecimento público, apenas seis $(5,6 \%)$ estavam contaminadas com coliformes totais e uma $(0,9 \%)$ com E. coli, ${ }^{(24)}$ enfatizando a importância do tratamento da água para a prevenção de contaminação da água subterrânea por microrganismos.

As principais fontes de abastecimento de água no meio rural são de origem subterrânea e em sua maioria não tratadas, fontes estas, sujeitas à contaminação devido a sua baixa profundidade e proximidade com a superfície do solo, estando expostas ao escoamento de água da chuva que carreiam impurezas; ${ }^{(25)}$ e como aproximadamente $30 \%$ das amostras de água do nosso trabalho foram coletadas durante o período de chuva, isto pode ter favorecido os altos índices de contaminação nessas fontes de consumo, já que as condições climáticas favorecem a propagação de patógenos.
Os grupos de DEC encontrados em nossa pesquisa foram ETEC e EAEC. ETEC é conhecida como o principal agente etiológico da "diarreia dos viajantes", e EAEC está associada à diarreia aguda e persistente, principalmente em crianças e idosos. ${ }^{(5)}$ A doença diarreica provocada por esses patógenos podem ser o resultado da ingestão de água e alimentos contaminados..$^{(1,5)}$

Em Londrina, Cestari et al. ${ }^{(26)}$ encontraram 36 $(12,2 \%)$ isolados de ETEC em 295 cepas de E. coli isoladas de água in natura para consumo humano; e um estudo realizado na França com amostras de água superficial de rio também encontrou uma porcentagem significativa de isolados de ETEC. ${ }^{(27)}$ Um estudo realizado na Nigéria com crianças entre 0-5 anos de idade com diarreia aguda mostrou que das 400 amostras de fezes coletadas, DEC foi encontrada em 51 amostras, e entre elas, 16 apresentavam características de ETEC. ${ }^{(28)}$

EAEC é um importante patógeno emergente em todo o mundo, e que além de causar diarreia pode colonizar o trato gastrointestinal do homem de modo assintomático, levando a uma inflamação intestinal crônica. ${ }^{(5)}$ Cepas de EAEC são frequentemente associadas à diarreia aguda em crianças, como demonstram estudos anteriores, ${ }^{(5,29)}$ podendo ser transmitidas através de água contaminada.

Ensaios de aderência em células HEp-2, cultivadas in vitro, permitem caracterizar fenotipicamente os diferentes padrões de adesão apresentados pelos patotipos de DEC, classificadas em: AL, AL-L, AD e AA, ${ }^{(5)}$ e de acordo com a diversidade dos resultados encontrados, podemos verificar a necessidade da investigação de genes de virulência para confirmar o patotipo de DEC.

O biofilme é um importante fator que contribui para a persistência da infecção bacteriana na mucosa intestinal, principalmente quando associada à EAEC, facilitando a evasão da bactéria ao sistema imunológico. ${ }^{(5)}$ Bactérias que se encontram em meio aquático estão mais propícias a formar um biofilme de maior intensidade para facilitar a permanência e sobrevivência no meio ambiente. ${ }^{(30)}$

Em Bengala Ocidental, Índia, foi realizada uma pesquisa de DEC em diferentes fontes de 
água potável e todos os isolados foram resistentes à ampicilina e tetraciclina, ${ }^{(31)}$ resistência similar a que encontramos em nossas cepas de ETEC.

Segundo a classificação de Clermont et al., ${ }^{(20)}$ as cepas de $E$. coli podem ser distribuídas em sete filogrupos: A, B1, B2, C, D, E, F, sendo os A, B1, $\mathrm{B} 2$ e $\mathrm{D}$ os mais encontrados. Em nosso estudo, as três amostras de ETEC se enquadraram no filogrupo B1 e a aEAEC no E. Uma pesquisa feita por Araújo et al. ${ }^{(32)}$ trabalhando com amostras de água e vegetais, verificou que o filogrupo B1 foi o mais predominante (56\%) em cepas de ETEC, seguido do A (22,3\%), e do grupo E, um dos menos encontrados, semelhante aos resultados obtidos em nosso estudo.

Em isolados de ETEC, os antígenos somáticos mais prevalentes são O6, O8, O78, 0128 e O153, e os antígenos H mais comuns são H12, H16, H21, H45 e H9, e, com uma frequência menor, os antígenos H7, H10 e H28. ${ }^{(33)}$ Em nosso estudo, um dos isolados de ETEC apresentou o antígeno O6, encontrado em outros trabalhos. Na Coreia do Sul, foram relatados dois surtos afetando alunos do ensino médio, sendo que um surto ocorreu em 2013 (107 alunos) e o outro em 2014 (1022 alunos), associados à ingestão de kimchi de repolho e rabanete, uma comida típica da Coreia do Sul, e o agente associado a esses surtos foi a ETEC do sorogrupo O6. ${ }^{(34)}$ As outras duas amostras de ETEC apresentaram os sorotipos OR:H21 e O17:H46 que não estão entre os mais prevalentes.

Em um estudo realizado por Benevides-Matos et al. ${ }^{(35)}$ com 1.156 isolados de E. coli em crianças com ou sem diarreia aguda, a maioria dos isolados de EAEC pertenciam aos sorogrupos O44, O55, O111, O125 e O127, sendo isolados de crianças que apresentavam um quadro clínico de gastroenterite aguda. O antígeno $\mathrm{O} 24$, encontrado em nosso estudo, não é comum em cepas de EAEC. ${ }^{(36)}$

\section{Conclusão}

Os resultados obtidos mostraram que a qualidade microbiológica da água para consumo no assentamento é insatisfatória e apresenta riscos à saúde dessa população. A presença de genes de virulência em cepas de $E$. coli indica que, além da água estar contaminada, abriga cepas com um potencial patogênico para causar infecção.

\section{Agradecimentos}

Agradecemos ao Laboratório de Virologia da Universidade Estadual de Londrina (UEL) pelo fornecimento de culturas de células HEp-2.

\section{Referências}

1 Grube JS, Ercumen A, Colford JM Jr. Coliform bacteria as indicators of diarrheal risk in household drinking water: systematic review and meta-analysis. PLoS One. 2014;9:e107429.

2 World Health Organization (WHO), United Nations Children's Fund (UNICEF). Progress on drinking water, sanitation and hygiene: 2017. [cited 2019 Jan 25]. Disponível em: https:// www.unicef.org/publications/index_96611. html\#

3 Ferreira DC, Luz SLB, Buss DF. Evaluation of simple diffusion chlorinators for decontamination of wells in a rural settlement in Amazonia, Brazil. Cien Saude Colet. 2016;21(3):767-76.

4 Clements A, Young JC, Constantinou N, Frankel G. Infection strategies of enteric pathogenic Escherichia coli. Gut Microbes. 2012;3(2):71-87.

5 Gomes TAT, Elias WP, Scaletsky ICA, Guth BEC, Rodrigues JF, Piazza RMF, Ferreira LCS, Martinez MB. Diarrheagenic Escherichia coli. Braz J Microbiol. 2016;47(Supp1 1):3-30.

6 American Public Health Association. Standard Methods for the examination of water and wastewater. 23 ${ }^{\mathrm{a}}$ ed. Washington: APHA; 2017.

7 Schuroff PA, Burgos TN, Lima NR, Lopes AM, Pelayo JS. Phenotypic and genotypic characterization of potentially pathogenic Escherichia coli from water treatment plants. Arq Ciênc Saúde. 2014;21(3):93-8. 
8 Lascowski KMS, Guth BEC, Martins FH, Rocha SPD, Irino K, Pelayo JS. Shiga toxinproducing Escherichia coli in drinking water supplies of north Paraná State, Brazil. J Appl Microbiol. 2012; 14(4):1230-9.

9 Vendruscolo JW, Waldrich TL, Saikawa GIA, Pelayo JS, Kobayashi RKT, Nakazato G, Rocha SPD. Novel multiplex PCR for detection of diarrheagenic Escherichia coli strains isolated from stool and water samples. Genet Mol Res. 2017;16(3):gmr16039760.

10 Paton AW, Paton JC. Detection and characterization of Shiga toxigenic Escherichia coli by using multiplex PCR assays for $s t x_{1}, s t x_{2}$, eaeA, enterohemorrhagic E. coli $h l y A, r f b_{\mathrm{O} 111}$, and $r f b_{\mathrm{O} 157}$. J Clin Microbiol. 1998;36(2):598-602.

11 Lima IF, Boisen N, Quetz Jda S, Havt A, de Carvalho EB, Soares AM, Lima NL, Mota RM, Nataro JP, Guerrant RL, Lima AÂ. Prevalence of enteroaggregative Escherichia coli and its virulence-related genes in a case-control study among children from north-eastern Brazil. J Med Microbiol. 2013;62(5):683-93.

12 Dudley EG, Thomson NR, Parkhill J, Morin NP, Nataro JP. Proteomic and microarray characterization of the AggR regulon identifies a pheU pathogenicity island in enteroaggregative Escherichia coli. Mol Microbiol. 2006;61(5):1267-82.

13 Schmidt H, Knop C, Franke S, Aleksic S, Heesemann J, Karch H. Development of PCR for screening of enteroaggregative Escherichia coli. J Clin Microbiol. 1995;33(3):701-5.

14 Andrade FB, Gomes TAT, Elias WP. A sensitive and specific molecular tool for detection of both typical and atypical Enteroaggregative Escherichia coli. J Microbiol Meth. 2014;106:16-8.

15 Aranda KR, Fagundes U Neto, Scaletsky IC. Evaluation of multiplex PCRs for diagnosis of infection with diarrheagenic Escherichia coli and Shigella spp. J Clin Microbiol. 2004;42(12):5849-53.
16 Schultsz C, Pool GJ, Van Ketel R, de Wever B, Speelman P, Dankert J. Detection of ETEC in stool samples by using non- radioactively labeled oligonucleotide DNA probes and PCR. J Clin Microbiol. 1994;32(10):2393-7.

17 Cravioto A, Gross RJ, Scotland SM, Rowe B. An adhesive factor found in strains of Escherichia coli belonging to the traditional infantile enteropathogenic serotypes. Current Microbiol. 1979;3:95-9.

18 Wakimoto N, Nishi J, Sheikh J, Nataro JP, Sarantuya J, Iwashita M, Manago K, Tokuda K, Yoshinaga M, Kawano Y. Quantitative biofilm assay using a microtiter plate to screen for enteroaggregative Escherichia coli. Am J Trop Med Hyg. 2004;71(5):687-90.

19 Clinical and Laboratory Standards Institute. Performance Standards for Antimicrobial Susceptibility Testing. $26^{\text {th }}$ ed. Wayne, PA, USA: CLSI supplement M100S; 2016.

20 Clermont O, Christenson JK, Denamur E, Gordon DM. The Clermont Escherichia coli phylo-typing method revisited: improvement of specificity and detection of new phylo-groups. Environ Microbiol Rep. 2013;5(1):58-65.

21 Brasil. Portaria $n^{\circ}$ 2.914, de 12 de dezembro de 2011. Dispõe sobre os procedimentos de controle e de vigilância da qualidade da água para consumo humano e seu padrão de potabilidade. Diário Oficial da República Federativa do Brasil, Brasília, DF, 13 dez. 2011.

22 Scorsafava MA, Souza A Stofer M, Nunes CA, Milanez TV. Avaliação físico-química da qualidade de água de poços e minas destinada ao consumo humano. Rev Inst Adolfo Lutz. 2010;69(2):229-32.

23 Burgos TN, Schuroff PA, Lopes AM, Lima NR, Pelayo JS. Água de consumo humano proveniente de poços rasos como fator de risco de doenças de veiculação hídrica. Rev Ciênc Saúde. 2014;16(1):34-8. 
24 Matsuchita HLP, Schuroff PA, Lima NR, Burgos TN, Lopes AM, Pelayo JS. Qualidade bacteriológica da água de abastecimento público de Centros Municipais de Educação Infantil (CMEI) das cidades de Londrina, Cambé, Ibiporã e Rolândia, PR. Rev Ciênc Méd Biol. 2014;13(1):60-3.

25 Amaral L, Filho NA, Junior ODR, Ferreira FLA, Barros LSS. Água de consumo humano como fator de risco à saúde em propriedades rurais. Rev Saúde Pública. 2003;37(4):510-4.

26 Cestari SE, Schuroff PA, Lima NR, Burgos TDN, Dambrozio AML, Pelayo JS. Caracterização genotípica de fatores de virulência de Escherichia coli enterotoxigênica isoladas de água para consumo humano. Rer Ciênc Méd Biol. 2016;15(2):139-43.

27 Kambire O, Adingra, AA, Yao KM, KoffiNevry R. Prevalence of Virulence Genes Associated with Diarrheagenic Pathotypes of Escherichia coli Isolates from Water, Sediment, Fish, and Crab in Aby Lagoon, Côte d'Ivoire. Int J Microbiol. 2017;1-8.

28 Ifeanyi CI, Ikeneche NF, Bassey BE, Al-Gallas N, Ben Aissa R, Boudabous A. Diarrheagenic Escherichia coli pathotypes isolated from children with diarrhea in the Federal Capital Territory Abuja, Nigeria. J Infect Dev Ctries. 2015;9(2):165-74.

29 Shah M, Kathiiko C, Wada A, Odoyo E, Bundi M, Miringu G, Guyo S, Karama M, Ichinose Y. Prevalence, seasonal variation, and antibiotic resistance pattern of enteric bacterial pathogens among hospitalized diarrheic children in suburban regions of central Kenya. Trop Med Health. 2016;44:39.

30 Wingender J, Flemming HC. Biofilms in drinking water and their role as reservoir for pathogens. Int $\mathrm{J}$ Hyg Environ Health. $2011 ; 214(6): 417-23$.

31 Batabyal P, Mookerjee S, Sur D, Palit A. Diarrheogenic Escherechia coli in potable water sources of West Bengal, India. Acta Trop. 2013;127(3):153-7.
32 Araújo S. Characterization of antibiotic resistant and pathogenic Escherichia coli in irrigation water and vegetables in household farms. Int $\mathrm{J}$ Food Microbiol. 2017; 257:192-200.

33 Nishimura LS, Ferreira LCS, Pacheco ABF, Guth BE. Relationship between outer membrane protein and lipopolysaccharide profiles and serotypes of enterotoxigenic Escherichia coli isolated in Brazil. FEMS Microbiol Lett. 1996;143:253-8.

34 Jaeseung S, Ki-Bok Y, Doo-Young J, SungSuk O, Kyung-Hwan O, Gyung TC, Seung WK, Seung-Hak C. Consecutive Outbreaks of Enterotoxigenic Escherichia coli O6 in Schools in South Korea Caused by Contamination. Foodborne Pathog Dis. 2016;13(10):535-43.

35 Benevides-Matos N, Pieri FA, Penatti M, Orlandi PP. Adherence and virulence genes of Escherichia coli from children diarrhoea in the Brazilian Amazon. Braz J Microbiol. 2015;46(1):131-7.

36 Ori EL, Takagi EH, Andrade TS, Miguel BT, Cergole-Novella MC, Gut BEC, Hernandes RT, Dias RCB, Pinheiro SRS, Camargo CH, Romero EC, Dos Santos LF. Diarrhoeagenic Escherichia coli and Escherichia albertii in Brazil: pathotypes and serotypes over a 6-year period of surveillance. Epidemiol Infect. 2018;19:1-9. 